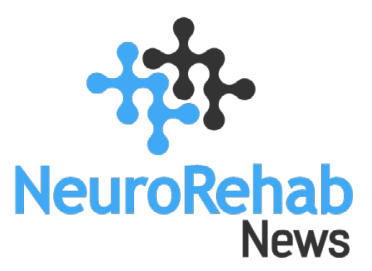

\title{
Terapia de Observación de Acciones
}

Ejercicio

\section{Infografía}

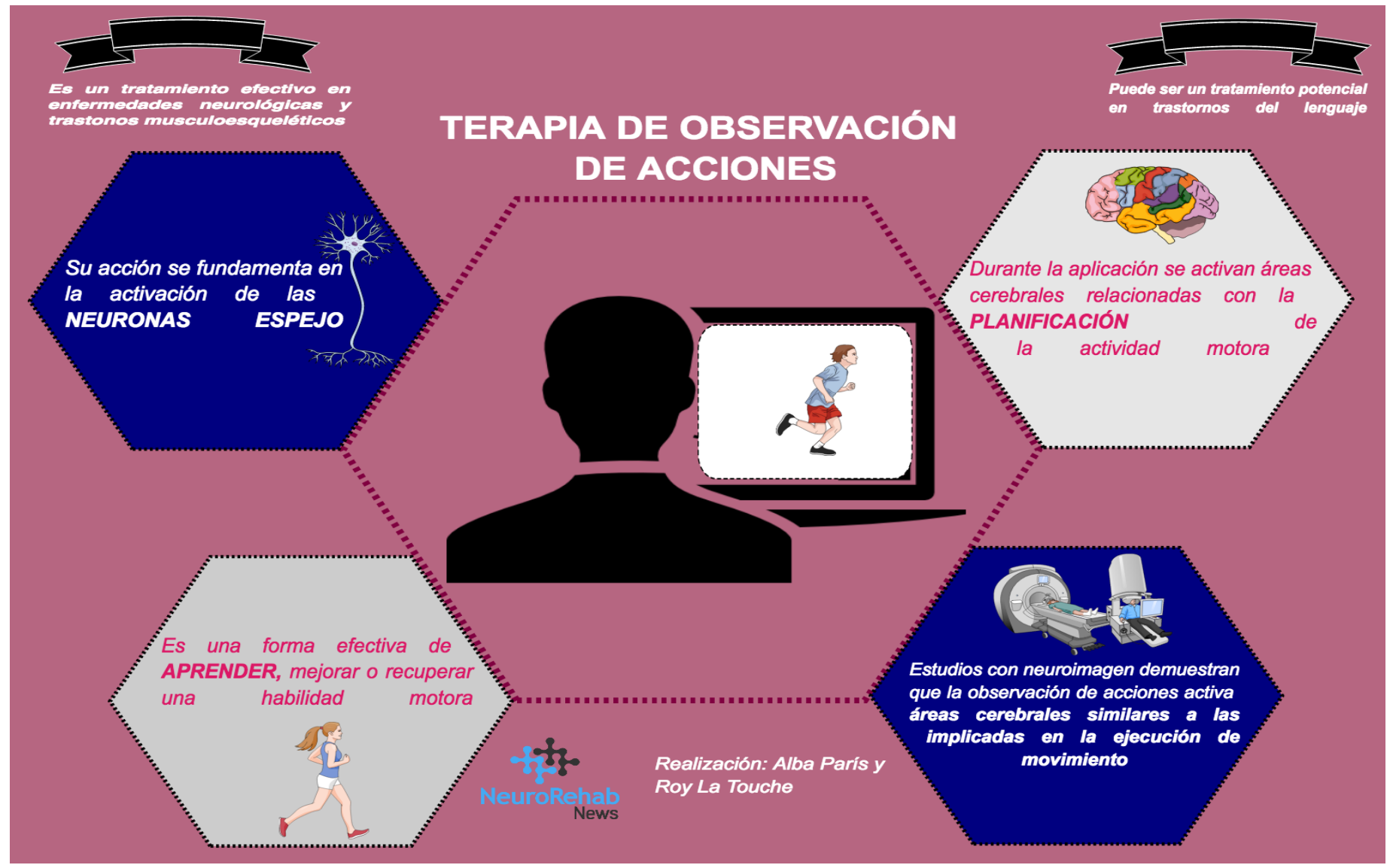

La terapia de observación de acciones, es un tratamiento que se basa en la observación de una acción realizada por otro individuo. Este tratamiento, desde el punto de vista neurofisiológico se fundamenta en la activación de las neuronas espejo. Investigaciones realizadas con neuroimagen describen que durante la observación de acciones se activan áreas de la corteza premotora, motora primaria y parietal, siendo estas determinantes en la ejecución y planificación del movimiento. Es importante destacar que la activación de estas áreas durante la terapia de observación es similar a la que se produce con la ejecución del movimiento.

Diversos estudios han demostrado que la terapia de observación de acciones es una forma efectiva de aprender o mejorar el rendimiento de una habilidad motora específica. Investigaciones recientes muestran que la terapia de observación de acciones facilita el aprendizaje motor y la construcción de la memoria motora. Este tipo de tratamiento ha sido utilizado con éxito tanto como una herramienta de rehabilitación (en enfermedades neurológicas y musculoesqueléticas) y en el entrenamiento deportivo. Evidencia reciente describe el potencial que puede tener este tratamiento sobre trastornos del lenguaje. 
La terapia de observación de acciones es aparentemente un tratamiento sencillo, sin embargo, tiene requerimientos muy exigentes en cuanto a la atención que debe mantenerse sobre la tarea. Por otra parte, es necesario que los pacientes tengan una actitud cooperativa y tengan un buen cumplimiento con el tratamiento.

\section{Sobre este artículo:}
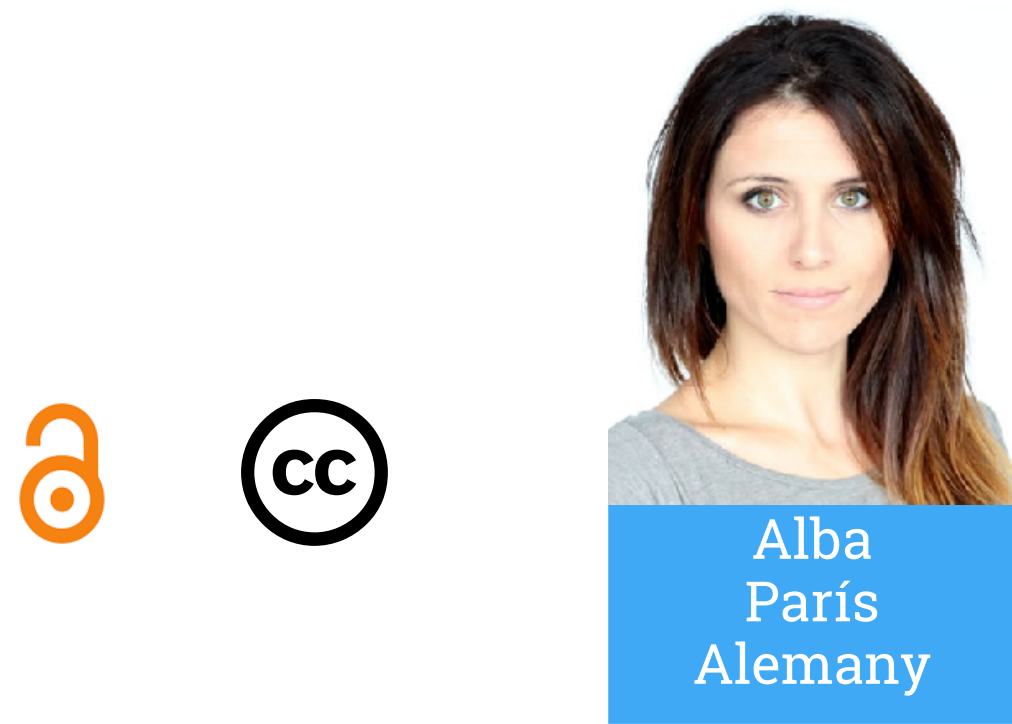

\section{Fuente /s:}

Buccino G. Action observation treatment:a novel tool in neurorehabilitation. Philos Trans R Soc Lond B Biol Sci. 2014 Apr 28;369(1644):20130185. doi: 10.1098/rstb.2013.0185.

Fuente de la imagen: imagen de NeuroRehabnews.com con fines unicamente ilustrativos.

Para citar este artículo: Paris-Alemany A, La Touche R. Terapia de Observación de Acciones. NeuroRehab News 2016 dic; (1)1: e0018 